\title{
Techniques in medical education
}

\section{Summary}

Effective care in hospitals and in the community requires doctors, nurses and other healthcare professionals to work together to achieve the best possible outcomes for patients. In the $U K$, a shift in emphasis towards a primary care led service and recent changes to the ways in which healthcare is funded and organised, are profoundly affecting traditional patterns of working. Boundaries which define the roles and responsibilities of individual professions are becoming less clear and there is increasing overlap of knowledge and skills. The provision of effective patient care now depends much more on the individual practitioner's understanding of the need to collaborate within and between healthcare teams in community settings and the care provided in hospitals. This paper describes some of the ways in which those providing education and training for the professions are seeking to create opportunities for learners which will not only help them to understand the complexities of working in a multiprofessional healthcare environment, but also enable them to develop the skills and attitudes they need for interprofessional working. However, it is not yet established whether 'learning together' during basic training will result in better 'working together' in practice. Higher education institutions are understandably cautious about adopting new learning methods which make extra demands on decreasing resources. More studies are therefore needed to show whether interprofessional learning during basic education has an impact on future working practice.

Keywords: education; interprofessional learning

Department of Health Care Education, Faculty of Medicine, The University of Liverpool, Liverpool, UK

G Parsell

J Bligh

Correspondence to Glennys Parsell, University Medical Education Unit, 3rd Floor UCD Building, Royal Liverpool University Hospital, Liverpool L69 3BX, UK

Accepted 28 May 1997

\section{Interprofessional learning}

\author{
Glennys Parsell, John Bligh
}

Interprofessional working is usually undertaken by healthcare teams comprising different professionals according to patient needs. Successful healthcare teams must share common goals and a commitment to providing the best possible care for patients. Team members must be willing to share and accept responsibility when making decisions and learn to understand and appreciate each other's strengths and limitations. They need to be open-minded and appreciate each other's opinions and be prepared to evaluate and assess their own behaviour as well as the functioning of the team. Crossing professional boundaries may mean exchanging secure for insecure feelings. Exposing personal limitations to others in the team can result in feelings of loss of status. Teamworking requires practitioners to be confident with their professional identities and willing to accept equal status. Working as a member of a team requires collaboration and negotiation skills which need to be learned. ${ }^{12}$

It is a short step to arrive at the conclusion that those who work together in practice for the benefit of patients should be provided with opportunities to learn together at all levels of their training. This paper describes recent interprofessional learning activity in the UK and elsewhere. Examples of shared learning, particularly those involving medical students, are used to illustrate the educational climate needed to implement and sustain initiatives.

\section{Interprofessional learning}

\section{A DEFINITION}

A clear distinction needs to be made between 'interprofessional', 'multiprofessional' and 'multidisciplinary', as they are frequently used interchangeably and indiscriminately.

- Interprofessional learning activities involve two professional groups, eg, physiotherapists and social workers; general practitioners and health service managers.

- Multidisciplinary learning activities involve members of differing branches of one profession, eg, district nurses, health visitors and practice nurses; general practitioners and hospital doctors.

- Multiprofessional activities involve three or more professional groups, eg, general practitioners, nurses and social workers.

Interprofessional approaches to learning are essentially about the integration and synthesis of knowledge to solve problems or explore issues. Conversely, 'multiprofessional' or 'multidisciplinary' approaches entail bringing together different perspectives to solve the same problem. The distinction between a profession and a discipline can be confusing as more and more former disciplines acquire individual professional status. ${ }^{4}$

Throughout this paper the terms 'interprofessional' and 'shared learning' are used, as these are most commonly recognised by practitioners in the UK.

\section{AN EDUCATIONAL PROCESS}

Interprofessional learning is an educational process through which students and practitioners are provided with structured learning opportunities for 'shared learning'. The goal of such learning is to enable learners to acquire knowledge, skills and professional attitudes they would not be able to acquire effectively in any other way. ${ }^{5}$

Teaching methods should adopt problem-orientated techniques which encourage discussion and critical thinking using interprofessional perspectives in small groups of learners, a teaching method well-documented as essential for adult learning. ${ }^{6-8}$ Shared learning does not mean that learners from different disciplines sit side by side in lectures (although this may sometimes still be appropriate) where learners are traditionally 'passive' recipients of facts and interaction is nonexistent. Joint teaching as a strategy is frequently adopted for economic reasons rather than sound educational principles. 


\section{The purpose of shared learning}

Planners of shared learning programmes usually incorporate two or three main goals:

- to enhance understanding of others' professional roles and responsibilities

- to help to develop skills needed for effective teamwork

- to increase knowledge of particular clinical skills or topics.

The latter is the reason most frequently used at a post-qualifying level to enhance continuing professional development, whereas the first two are most frequently the key objectives in undergraduate shared-learning programmes. ${ }^{9}$

There is evidence to support the view that shared learning can help to break down stereotypical views that professionals hold about one another. ${ }^{6}$ Such opportunities increase and deepen understanding of each other's roles and responsibilities, strengths and limitations, and help to develop communication and interpersonal skills. Most importantly, it is claimed that shared learning enhances the capability of individuals to work successfully as members of teams, thereby increasing their efficiency when they become practitioners, the ultimate aim being to improve the quality of patient care. ${ }^{10}$ These assumptions, however, have yet to be supported by evidence. ${ }^{11}$

\section{Who supports interprofessional learning?}

In the last decade there has been a considerable increase in overt support by the government, eg, in the white paper, Caring for people. ${ }^{12}$ This document set out the community care reforms in the 1990 government legislation (National Health Service and Community Care Act) and implementation which followed in 1993. Emphasis was placed on primary healthcare teams and co-operation between agencies to provide healthcare services based on assessment of the needs of users. Other professional bodies have demonstrated support for shared learning in educational initiatives (eg, the Royal College of General Practitioners, the UK Central Council for Nursing, and the Central Council for Education and Training for Social Work in their Statement on the development of interprofessional education and training for members of the primary health care team, Joint Committee on Primary Health Care, London, 1983). The General Dental Council also believes that “...all, or most courses should involve interdisciplinary collaboration and be centred on topics rather than subject teaching." 14 The General Medical Council, whilst not explicitly supporting interprofessional working in Tomorrow's doctors, does recommend that undergraduate courses include:

- the development of knowledge and understanding of health promotion, disease prevention and management in the context of the whole individual and their place in the family and society

- an awareness of personal limitations, willingness to seek help when necessary and ability to work as a member of a team

- communication skills needed for teamwork

- problem-oriented small group learning. ${ }^{15}$

The World Federation For Medical Education also emphasized the need for multiprofessional learning for doctors. The recommendations of the World Summit on Medical Education held in Edinburgh in 1993 state: "Multiprofessional education, where members of different health professions are trained together, establishes and enhances the ethos of teamwork, and the essential collaboration of medicine with allied health personnel." This action will produce "more effective doctors who can work as members of health care teams, with enhanced respect for colleagues, and for the benefit of patients and communities." 16

In 1984 the World Health Organisation emphasized 'multiprofessional education' as a means of achieving Health for all by the year 2000 and four years later published Learning together to work together for health: the team approach.$^{17}{ }^{18}$ This latter report was helpful in providing details of many shared learning programmes throughout the world, and by encouraging development of further initiatives at both pre- and post-qualifying levels.

The UK Centre for the Advancement of Inter-professional Learning (CAIPE) was formed in 1987 and has become a focal point for educators, practitioners and programme planners of shared learning in healthcare in the UK. ${ }^{19} \mathrm{CAIPE}$ published a set of principles to guide interprofessional learning which is based on the experience of many practitioners and teachers in healthcare education (box 1). INTERACT, also formed in 1987, provides an informal network for professionals in Scotland. During the same year, the European Network for the Development of Multiprofessional Education was constituted, thus encouraging international collaborative working and learning. ${ }^{20}$ 


\section{Postgraduate education and training}

Interprofessional initiatives in postgraduate and continuing professional development have been established for many years. The child abuse enquiries of the 1980s have focused attention on the need for more inter-agency co-operation and collaboration..$^{21}{ }^{22}$ Educational initiatives around teamworking undertaken in primary care and in the community show that working in teams requires high levels of specific skills and collaboration, and a change in attitudes. ${ }^{23}$ An organisational structure enabling such teams to function must also be in place. Willingness to work in teams does not mean that they function well and are effective. ${ }^{24}$

Master's programmes which focus on interprofessional working and learning have significantly increased, eg, the multiprofessional master's degree in healthcare at the University of Exeter, and the master's degree in interprofessional health and welfare studies at South Bank University. A master's course in community and primary care was also established at the Marylebone Centre Trust in 1990, which aims to produce 'reflective practitioners' through interprofessional practice. ${ }^{825}$

\section{When does interprofessional learning occur?}

It is after qualification that most shared learning initiatives take place. A CAIPE survey of interprofessional learning in the UK in 1988 showed that the majority of shared learning initiatives were in the field of postgraduate continuing education, $96 \%$ involving district nurses and/or health visitors; $50 \%$ of these included social workers and $33 \%$ included general practitioners and/or midwives. They were usually one-off initiatives of one day or less (53\%) or between two to four days $(28 \%)$. Their key learning objectives were to promote understanding of professional roles and to develop teamwork skills. ${ }^{26}$

During 1995, CAIPE commissioned a follow-up survey. ${ }^{27}$ This survey showed that, of 455 valid initiatives reported, only $12.5 \%$ were at undergraduate or prequalifying level. The authors of the report state that "additional information sent by respondents indicated that initiatives known to them substantially exceeded the number reported."

\section{Undergraduate medical education}

If shared learning is thought to be such a good thing, why are there so few examples of undergraduate shared learning involving medical students? Although the rhetoric supports the idea of interprofessional learning as a component of medical school courses, in reality there are very few examples of shared learning involving medical students from which lessons can be learned.

Proponents of shared learning are convinced that if early opportunities are provided for students to learn together, for example, at the beginning of year one, then entrenched attitudes and negative stereotyping towards other professional groups would be averted. ${ }^{6}$ The early promotion of teamwork and collaborative skills are other specific objectives. Increased knowledge and understanding of other professional groups by students, combined with greater understanding of themselves as future practitioners would encourage and foster attitudes of respect and trust.

However, individual characteristics of medical and dental courses and those of nursing and professions allied to medicine present major obstacles. These obstacles place enormous constraints on bringing any two or more student groups together, even when there is enthusiasm to do so. Time-tabling is a major difficulty as core areas of learning and clinical experience are placed at different levels in courses. Frequently there are huge discrepancies in numbers of students in departments and contrasting learning and assessment methods have to be taken into account. Planning and implementation meetings present similar difficulties as staff in each department have varying commitments and responsibilities. Opportunities have to be identified and initiatives piloted and evaluated before convincing sceptical colleagues of the worth of the exercise. Despite these and many other issues, there is a growth in shared learning programmes involving medical students, some of which are described below.

\section{Approaches to interprofessional learning}

\section{LINKÖPING UNIVERSITY}

A new Faculty of Health Sciences was established in 1986 at Linköping University in Sweden. ${ }^{28}$ An integrated approach using problem-based learning as its main teaching method is used to deliver a multiprofessional course to students 


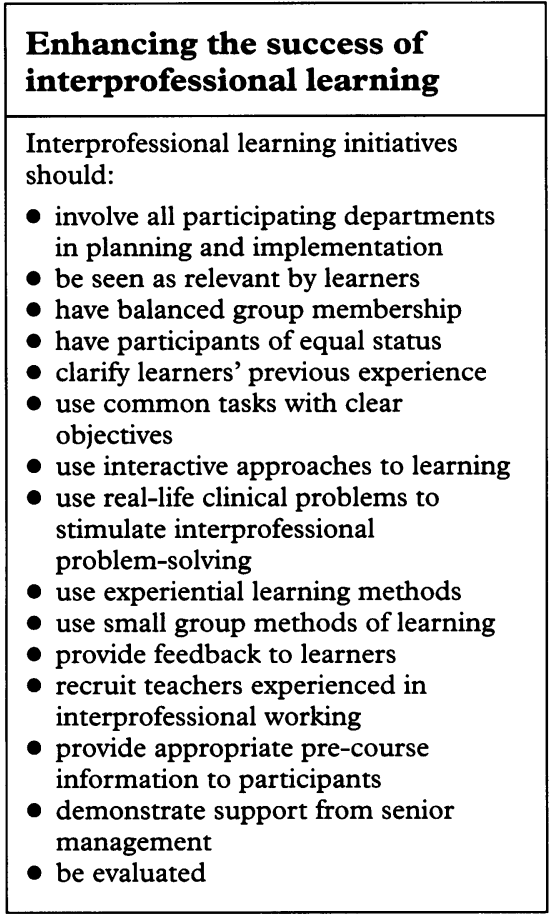

Box 2 from six healthcare disciplines. For the first 10 weeks of their courses and prior to their specific disciplines, students from medicine, nursing, physiotherapy, occupational therapy, medical laboratory technology and social work learn together about Man in society. The course is orientated towards the social and behavioural sciences in the context of health promotion, disease prevention and a holistic view of healthcare in the individual. It includes four main themes: human development, social structures, conditions for health and healthcare, and the ethics of healthcare and philosophies of life. Additional shared learning occurs in the following three semesters when separate days of shared learning are arranged around common themes. Practical training also provides opportunities for students to learn together.

Throughout their courses students learn through problem-based learning. This educational process uses real-life scenarios as the trigger for learning requiring integration and synthesis of various forms of knowledge. Individual and group research takes place during allotted time in each two and a half week module, and a tutorial system allows students to develop self-directed learning and evaluation skills. These features of problem-based learning are particularly suited to interprofessional learning.

The introductory module is assessed during a three and a half hour examination using a scenario. Students are not graded, but are marked pass or fail and can be re-assessed if necessary. A further assessment of a group project covering eight of the 10 weeks takes place at the end of the module. Topics are related to a health and environment theme. Courses are assessed using the Swedish credit accumulation system which includes the interprofessional elements. Man in society accounts for $25 \%$ of the credits awarded for year one, and interprofessional learning in total accounts for $12 \%$ of the professional qualification. Linköping is now considering extending its shared learning programme to the final year.

UNIVERSITY OF BRISTOL

This shared learning programme based at the University Departments of Social Work and Mental Health, involved the Departments of Nursing and Applied Social Studies at the former Bristol Polytechnic. ${ }^{29}$ During 1986 changes in the undergraduate medical course allowed one week of the final year to be allocated to shared learning. The course was mandatory for all students. Groups of students in the final year of their training in various healthcare disciplines, including nurses and social workers, were matched with final year medical students. Students selected two and a half days of sessions of shared learning during the week. Activities were organised in a variety of settings with a selection of health-related topics. A doctor and a social worker led each 'event' after being briefed about the educational foundation of the shared learning programme. The learning objectives were:

- to examine similarities and differences in the attitudes and skills of members of the other profession

- to acquire a knowledge of their respective roles and duties with respect to the topic under consideration

- to explore methods of working together co-operatively and effectively in the best interests of their patients/clients.

The programme was designed according to social psychological variables derived from studies of the contact hypothesis. This approach suggests that when two conflicting groups are brought together attitudes can indeed be modified if particular variables are incorporated into the programme. ${ }^{30}$ These variables are:

- institutional support

- positive expectations

- successful joint work

- co-operative atmosphere

- a concern and understanding of differences and similarities

- equal status

- the perception that members of the group are typical and not just exceptions to the stereotype

- positive feedback to students.

The programme of shared learning was designed with this list in mind. Quantitative results of the evaluation (this is the only known study of shared learning in the UK which has quantified shifts in attitude changes) showed that although changes in attitudes were not large, attitudes towards each professional group showed statistically significant improvement. There was also an increase in knowledge of the other's roles, attitudes, skills and duties. Because the course was compulsory, a few medical students showed resentment in their written feedback. Student responses demonstrated that the contact hypothesis factors that planners had built into the course were present. An evaluation of an earlier 
identical course showed that an increase in changes had occurred in the later course. This result was attributed to the greater length of intergroup contact on the later course, namely two and a half days instead of one day. This supports the idea that increased and regular contact will lessen erosion of newly acquired attitudes and reinforce learning.

OTHER SHARED LEARNING PROGRAMMES

There are other examples of well-established shared learning programmes, for example, at the Universities of Limburg. Maastricht, The Netherlands, and the University of Bobigny, Paris Nord, France, which show further aspects of diversity and commitment. ${ }^{3132}$

The University of Limburg uses real problems encountered in clinical practice as a means of stimulating learning in each of seven health sciences professions. Students share the same course during the first year. For each successive year they continue to share learning for half of their time and study their chosen discipline for the other half. They are able to graduate in one of seven health professions.

The University of Bobigny established a two-year programme in 1984 which allowed students to discover which health science profession they would ultimately like to pursue. The programme was modular and concentrated on aspects of community health using lectures and small-group learning and practical and research-based elements. During the following two years, students were guided towards making an informed choice of career in the area of healthcare which suited them best. Professional examinations at the end of the programme allowed them to enter their chosen profession.

One of the earliest and most innovative attempts to introduce interprofessional learning with medical students took place at The University of British Columbia. ${ }^{33}$ As part of a large project several experiments in interprofessional learning were designed and implemented by a committee drawn from all disciplines, including the student body. Interprofessional learning was tried with large groups in both didactic and clinical courses. Communication between students only occurred during mixed seminars with trained facilitators, where knowledge was deliberately applied to different professional groups. The lack of support from the majority of faculty also hindered success. At the University of Nevada in Reno, positive outcomes were reported of a team training course involving mixed discipline groups of students and at the University of Pennsylvania positive changes in attitudes were recorded. ${ }^{34} 35$

New initiatives are also reported in New South Wales, Australia. ${ }^{36}$ At the University of Adelaide, large numbers of students from nine disciplines, including medicine, are provided with shared learning opportunities at two points in their undergraduate courses. The aim is to increase students' understanding of primary healthcare from interprofessional perspectives. Learning is based on a number of healthcare issues all of which have the same broad learning objectives. Assessments contribute to the overall qualification. ${ }^{37}$

In the UK, St Bartholomew's School of Nursing and Midwifery and the School of Medicine designed and developed a multiprofessional clinical skills facility enabling newly qualified nurses and final-year medical students to learn clinical and communication skills together. The course centred around the management of a patient with diabetes and shared learning of six associated clinical skills. Students claimed that the experience had altered their perceptions and would influence their future practice. A separate community module involved small teams of medical, dental and nursing students learning about community issues through patient-partner attachments. Design and implementation issues relating to shared learning were highlighted by the initiative and used for future improvement. ${ }^{38}$

\section{Discussion}

When considering interprofessional learning, questions about when shared learning should occur, with what frequency, content and learning methods, where it should take place and why it is appropriate, are all questions which need to be considered.

The above examples show how different shared learning initiatives can be, although there are clearly many similarities. At Linköping, the foundation programme is a strategy for achieving the WHO target Health for all 2000. The Bristol programme was part of the final year of each discipline involving two institutions, where changing attitudes and learning about other professional groups were key objectives. Other programmes concentrate learning on 'generic' or 'core' learning such as communication, teamworking, research method or information technology. All programmes recognise that small groups using real-life 


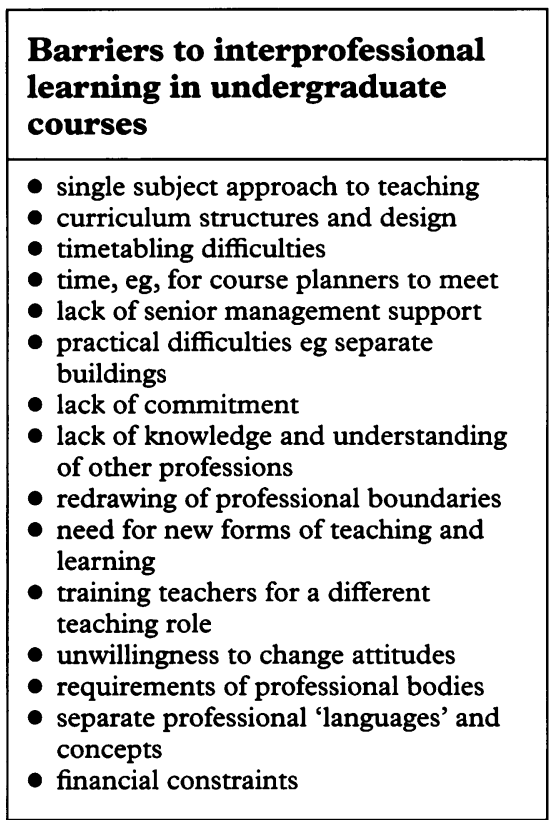

Box 3

\begin{tabular}{l}
\hline Summary points \\
\hline Interprofessional learning: \\
is based on a holistic approach to \\
patient care \\
places patient care at the centre of \\
learning \\
involves interactive learning between \\
different professional groups \\
develops knowledge and \\
understanding of other professions \\
involved in the delivery of healthcare \\
means acceptance of a different set of \\
values about teaching and learning \\
reflects the needs of the healthcare \\
team \\
further evidence is required to \\
demonstrate that interprofessional \\
learning at pre-qualifying level is \\
carried over to professional practice \\
and will ultimately improve patient \\
care
\end{tabular}

Box 4 problems stimulate learning through experience and reflection. As with many programmes, the duration of professional contact varies considerably although most appear to be one day, or between two and four days. ${ }^{27}$ Another major difference is shown to be in assessment. At Linköping, assessment methods, both formative and summative, contributed to the final professional qualification of students, thereby confirming its academic value. Motivation in these circumstances is unlikely to be an issue.

The introduction and development of shared learning programmes is often due to the dedication and commitment of a small number of staff who attempt to overcome the many barriers they find along the way. Some of these structural barriers are outside their immediate control. Time-tabling difficulties, individual professional course content and organisation, irreconcilable clinical attachments and the requirements of validating bodies, all mitigate against shared learning. Even the physical location of departments and schools can frustrate attempts to get students together for even the briefest of periods. For shared learning to be a part of undergraduate courses a number of factors need to be present and barriers overcome (box 3).

First, there should be overt support at the most senior levels for shared learning by those who decide educational policy and control resources. Changes need to be made to course structures, organisation and attitudes if shared learning is to take place at all.

Second, interprofessional learning needs to be planned, organised and delivered by all involved departments so that a shared sense of commitment and value is conveyed to students.

Third, extra resources need to be made available, for example, time to prepare course materials and meet colleagues, and for staff development. Extra space will be needed to accommodate small groups. It may be possible to share resources, for example, those needed for clinical skills teaching. In reality, these extra resources are viewed as a serious obstacle to shared learning and require institutional strategies to ease the situation.

Fourth, students need to feel confident that the content of learning has relevance to their chosen field and that, by sharing learning with other professional groups, benefits will accrue which may not be possible using any other strategy. Students need to share the same objectives and have similar expectations. It is essential that planned activities are interesting, rooted in clinical practice and use learning techniques which allow students to explore the realities of patient problem-solving within a service delivery context. It is ironic that those skills and abilities, apart from specialist occupational knowledge, which future employers consider essential for working in the health service such as team-working, communication and interpersonal skills, are the ones which are least valued by medical students. Students place most value on those subjects which are assessed and since these 'soft' components are not generally part of their assessment, they can be devalued.

Fifth, tutors need to act as role models for students and should have experience themselves of interprofessional collaboration. They may need training for their roles as tutors where there is a radical change in teaching and learning methods, for example, in the use of problem-based learning.

Finally, evaluation must be an integral part of each programme to establish the effectiveness of the programme in meeting its educational, institutional and cultural objectives.

\section{Conclusion}

Evaluation evidence from a number of studies confirms that shared learning at undergraduate level can indeed change attitudes and increase understanding about the roles of other professionals when based on sound educational principles. ${ }^{99}{ }^{31} 38$ However, unless there is support and reinforcement of new knowledge by regular practical experience or further shared learning, erosion of knowledge and skills is likely to be significant. Previous attitudes acquired through a long process of professionalisation will be re-established, or even strengthened.

There are many difficulties which need to be overcome if shared learning is to become a regular occurrence at the pre-qualification level. Each institution needs to seek out opportunities according to their own circumstances, where enthusiasm is greatest, where timetables can be adjusted, where core content overlaps, and where learning and teaching methods offer the greatest 'fit'. Resources must be considered a priority as more space is needed for small-group working and time needed for teachers in different professions to come together to plan, implement and evaluate and to produce the necessary course materials. Students also may need more resources for self-directed study time and tutors will need 
to be trained to teach or facilitate interprofessional small group learning. All of these require the ethos of the institution to be one of openness and receptive to change through support from senior management teams.

There is still a lack of evidence to support the assumptions that interprofessional learning in undergraduate courses will improve collaboration and team-working in future practice, or that there will be improved quality of patient care. More research is needed to confirm or refute these assumptions, for example, through long-term follow-up of students from early shared learning experiences into their professional lives. Only then can we identify good educational practice needed for undergraduate shared learning which can truly meet these goals. Such evidence may then convince policy-makers that the effort is worthwhile.

1 Engel C. A functional anatomy of teamwork. In: Leathard A, ed, Going inter-professional workin together for health and welfare. London: Routledge, 1994; pp 64-74.

2 Dingwall $R$. Problems of teamwork in primary care. In: Clare AW, Corney RH, eds, Social work and primary health care. London: Academic Press, 1982; pp 81-103.

3 Leathard A. Going interdisciplinary. Nursing 1991; 4(33):9-11.

4 Becher T. Academic tribes and territories. Milton Keynes: SRHE/Open University Press, 1989.

5 Funnell P. Exploring the value of interprofes sional shared learning. In: Soothill K, Mackay $\mathrm{L}$, Webb C, Interprofessional relations in healt care. London: Edward Arnold, 1995; pp 163 71 .

6 Areskog NH. The need for multi-professional health education in undergraduate studies (editorial). Med Educ 1988;22:251-2.

7 Knowles M. The modern practice of adult education: andragogy versus pedagogy. New York: Association Press, 1970

8 Schön D. Educating the reflective practitioner: towards a new design for teaching and learning in towards a new design for teaching and learning

9 Forman D, Jones I, Morley J. Shared manageForman D, Jones I, Morley J. Shared manage-
ment learning at the University of Derby. ment learning at the University
Interprofessional Care $1994 ; 8: 275-8$.

10 Carpenter J. Interprofessional education for medical and nursing students: evaluation of programme. Med Educ 1995;29:265-72.

11 Barr H. Evaluating interprofessional education. CAIPE Bull 1995;10:22

12 Secretaries of State for Health and Social Security. Caring for people: community care in the next decade and beyond. $\mathrm{Cm}$ 849. London: HMSO, 1989.

13 Steele J. 'CCESTW with ENB'. CAIPE Newslett 1990;2 (Autumn): 5.

14 General Dental Council (GDC). A strategic framework for dental education (discussion document). London: GDC, 1994.

15 General Medical Council (GMC). Tomorrow' doctors. London: GMC, 1993.

16 Walton HJ, ed. World Federation for Medical Education. Proceedings of the World Summi on Medical Education. Med Educ 1993;28 (suppl 1):140-9.

17 World Health Organization (WHO). Health for all 2000. Copenhagen: WHO Regional Office, 1984 .

18 World Health Organization (WHO). Learning together to work together for health. Report of WHO study on multi-professional education of health personnel. Geneva: WHO Technical Report Series 769, 1988.

19 Horder J, ed. What is CAIPE? CAIPE Newslet 1991;3 (Autumn): 1.

20 Goble REA. Multi-professional education in Europe. In: Leathard A, ed. Going interprofessional: working together for health and welfare. London: Routledge, 1994; pp 176-87.

21 Butler Sloss E. Report of the inquiry into child abuse in Cleveland 1987. Cm 413. London: HMSO, 1988.

22 Department of Health (DOH). Working together a guide to arrangements for inter-agency cooperation for the protection of children from abuse. London DOH, 1991.

23 Areskog NH. Multi-professional team training within the health care sector. WHO Report ICP HMD 136/7. Copenhagen: WHO Office for Europe, 1986.

24 Pereira Gray D. Training for general practice. Plymouth: Macdonald and Evans, 1982.

25 Storrie J. Mastering interprofessionalism - an enquiry into the development of Master's programmes with an interprofessional focus. $\%$ interprofessional Care 1992;6:258-9

26 Shakespeare H, Tucker N, Northover J. Report of a national survey on inter-professional education in primary health care. London: Centre for the Advancement of Inter-professional Education in Primary Health and Community Care, Institute of Community Studies, 1989.

27 Barr H, Waterton S. Interprofessional education in health and social care in the United Kingdom. London: CAIPE, 1996.

28 Areskog NH. Multi-professional education at undergraduate level. In: Soothill, Mackay I
Webb C. Interprofessional relations in health care. London: Edward Arnold, 1995; pp 125-39.

29 Carpenter J. Interprofessional education for medical and nursing students: evaluation of programme. Med Educ 1995;29:265-72.

30 Hewstone $M$, Brown RJ. Contact is not enough an intergroup persepctive on the "contact hypothesis". In: Hewstone M, Brown R J, eds. Contact and conflict in intergroup encounters. Oxford: Blackwell, 1996; pp 1-44.

31 Rijksuniversiteit Limburg. The Maastrich educational system. Maastricht: University of Limburg, 1989.

32 d' Ivernois, J-F. The Faculty of Medicine of Bobigny University, Paris Nord. EMPE Newslett $1987 ; 1-3$.

33 Szasz G. Interprofessional education in the health sciences. Millbank Mem Fund $Q$ 1969;2: 449-75.

34 Edinberg MA, Dodson SE, Veach TL. A preliminary study of student learning in health care teams. F Med Educ 1978;53:667-71.

35 Bassoff BZ. Interdisciplinary education as a facet of health care policy: the impact of attitudinal research. $\mathcal{F}$ Allied Health 1981;6:280-6.

36 Leathard A, ed, Interprofessional developments in Britain: an overview. In: Going interprofessional: working together for health and welfare. London: Routledge, 1994; pp 3-37.

37 Hiller J, Woodward A, Moss J. Development and evaluation of problem-oriented, multiprofessional courses in community health Teaching development grant report, 1990, Teaching development grant report, 1990, Davidson L, Lucas J. Multiprofessional education in the undergraduate health professions curriculum: observations from Adelaide, Linköping and Salford. F Interprofessional Care 1995;9:163-76.

38 Centre for the Advancement of Interprofessional Learning (CAIPE). Developing shared learning between medical and nursing students. Report of two seminars. London: CAIPE, 1994; pp 6-12. 